\title{
Smoking-Related Glomerulopathy: Expanding the Morphologic Spectrum
}

\author{
Steven P. Salvatore ${ }^{a}$ Megan L. Troxell ${ }^{b}$ Douglas Hecox ${ }^{c}$ Kevin R. Sperling ${ }^{d}$ \\ Surya V. Seshan ${ }^{a}$ \\ ${ }^{a}$ Weill Cornell Medical College, New York, N.Y., ${ }^{b}$ Oregon Health and Science University, Portland, Oreg., \\ ${ }^{\mathrm{C}}$ Renal Care Consultants, Medford, Oreg., and ${ }^{\mathrm{d}}$ Clinical Renal Associates Ltd., Upland, Pa., USA
}

\section{Key Words}

Smoking-related glomerulopathy · Proteinuria $\cdot$ Chronic kidney disease $\cdot$ Idiopathic nodular glomerulopathy

\begin{abstract}
Background: Chronic smoking and hypertension may lead to smoking-related nodular glomerulopathy (SRNG), a wellrecognized entity that clinically and pathologically mimics nodular diabetic nephropathy (DN). However, like DN, diffuse mesangial sclerosis may occur in this setting without nodules. Methods: The clinicopathologic features of 10 nondiabetic patients with a long smoking history diagnosed from 2003-2012 showing diffuse mesangial glomerulosclerosis (6) or SRNG (4) were analyzed. Results: Nine of 10 patients were men, aged 58-80 with a 20-58 pack-year smoking history. None of the patients manifested diabetes, but all of them had hypertension. Numerous other cardiovascular comorbidities were present. At biopsy, the mean creatinine was $1.9 \mathrm{mg} / \mathrm{dl}$ (range 1.4-3) and the mean proteinuria was $3.9 \mathrm{~g} / 24 \mathrm{~h}$. The renal pathologic findings were similar in all patients except mesangial nodules in SRNG. Global glomerulosclerosis was seen in 6-72\% of glomeruli (mean 31\%), glomerulomegaly in all cases, and a range of interstitial fibrosis in $10-70 \%$ (mean $43 \%$ ). Moderate $(40 \%)$ and severe (50\%) arteriosclerosis and arteriolar hyalinosis (80\%) were also ob-
\end{abstract}

served. Glomerular hilar or mesangial neovascularization was prominent. Endothelial swelling, subendothelial widening, and new basement membrane formation suggesting chronic healing thrombotic microangiopathy (TMA) was noted in $80 \%$. No immune complexes were localized. Conclusions: Kidney biopsies from patients with proteinuria and chronic renal insufficiency in the setting of prolonged smoking and hypertension show either diffuse or nodular mesangial glomerulosclerosis. Chronic glomerular mesangial and endothelial injury associated with smoking leads to a chronic TMA appearance in the appropriate setting, even in the absence of mesangial nodule formation.

๑) 2015 S. Karger AG, Basel

\section{Introduction}

Cigarette smoking has been linked to a spectrum of clinical renal diseases as well as biopsy-proven renal lesions resembling nodular diabetic nephropathy. Smoking is responsible for both intra- and extra-renal vascular pathology, and often long-term smoking is associated with chronic hypertension.

Kidney biopsies in long-term smokers, generally performed for proteinuria and renal insufficiency, have mostly reported nodular mesangial glomerulosclerosis in

\section{KARGER 125}

(c) 2015 S. Karger AG, Base

0250-8095/15/0411-0066\$39.50/0

E-Mail karger@karger.com

www.karger.com/ajn
Steven P. Salvatore, MD

Weill Cornell Medical College

525 E 68th St., Box 69

New York, NY 10065 (USA)

E-Mail sts9057@med.cornell.edu 
the absence of diabetes or other superimposed glomerular immune complex disease or other lesions [1-6]. The term 'ING' (idiopathic nodular glomerulosclerosis) was first coined by Herzenberg et al. to describe the glomerular morphology resembling nodular diabetic nephropathy (DN) (with expanded mesangial matrix, glomerular and tubular basement membrane thickening, vascular hyalinosis), but without clinical evidence of impaired glucose metabolism.

While smoking-related nodular glomerulosclerosis (SRNG) seems to be a rare diagnosis with only $0.4 \%$ of native biopsies in 1 study, greater than 60 cases in total have been described in the literature. The largest study by Markowitz et al. postulated that smoking and hypertension were common risk factors, present in $91 \%$ and $96 \%$ of cases respectively - a finding that has been corroborated in subsequent studies [1]. These patients also had coexisting non-renal vascular pathology (peripheral vascular disease, coronary artery disease, stroke, aortic aneuryms) in up to $50 \%[2,5]$, and an underlying endothelial injury related to elevated blood pressure and smoking has been proposed. A review in 2007 by Nasr and D'Agati proposed the term 'smoking-associated nodular glomerulosclerosis' to more definitively implicate the role of smoking initiated by endothelial injury in this process [7].

In smoking-related glomerulopathy (SRG), lesions resembling chronic thrombotic microangiopathy (TMA) were specifically described by Liang et al., but TMA is also noted in the pathologic descriptions of nearly all reports of ING $[1-4,7]$. It is well known that endothelial injury is central in the development of TMA. Chronic TMA is characterized by endothelial swelling along the glomerular basement membranes with varying detachment, subendothelial lucent areas, new basement membrane layers and cellular interposition within the resultant space, in the absence of immune complex deposits. This gives rise to a double contour appearance of the glomerular capillary walls by light microscopy. A glomerular lesion similar to or diagnostic of chronic TMA would support endothelial injury as the basis for these pathologic changes.

SRG histologically mirrors DN to the renal pathologist by light microscopy and ultrastructural findings with glomerular mesangial nodule formation, tubular basement membrane and glomerular basement membrane thickening, and exudative lesions (arteriolar hyalinosis, fibrin cap, capsular drop). Clinically, the patients present with proteinuria and renal insufficiency, also similar to cases of $\mathrm{DN}$, but without evidence of clinical diabetes or impaired glucose metabolism. DN is known to pathologically have a range of glomerular morphologic changes from isolated glomerular basement membrane thickening to diffuse expansion of the mesangial matrix to frank nodule formation to diffuse global glomerulosclerosis, depending on the duration of DM and the severity of glomerular injury [8]. Diffuse mesangial glomerulosclerosis in this context refers to the global, non-nodular involvement of the mesangium with increased matrix, not necessarily the percentage of glomeruli involved. We proposed a similar spectrum of pathology in SRG, which may not always reveal mesangial nodule formation, perhaps requiring other concomitant insults/factors for the development of the varied morphologic features.

\section{Methods}

The renal pathology archives at Weill Cornell Medical College and Oregon Health and Science University were retrospectively reviewed for cases of diffuse or nodular mesangial glomerulosclerosis in the absence of a clinical history of diabetes from January 1, 2003 through December 31, 2012. Twenty-four total biopsies were initially identified with diffuse or nodular mesangial glomerulosclerosis without a clinical history of diabetes. Sixteen of the 24 were diffuse alone, while 8 revealed nodular sclerosing changes. Ten cases fit the criteria where diabetes mellitus was adequately excluded. All ten identified that patients did not have clinical stigmata of diabetes including all with normal fasting glucose levels both prior to and during the follow-up period. In addition, Hgb A1c testing was performed in 5 cases and the results were found to be within the normal range. The remaining cases, 10 diffuse and 4 nodular cases were excluded from the study: 1 patient was taking oral anti-hyperglycemic agents despite 'no history of diabetes', 2 had mildly elevated fasting glucose (107 and 118), 1 had a history of gestational diabetes, 1 developed diabetes shortly after biopsy, 8 did not have enough information/testing performed to definitely exclude a diabetic state, and the final excluded case did not have diabetes and also a smoking history.

In ten cases, 6 with diffuse and 4 with nodular mesangial glomerulosclerosis, the clinicopathologic characteristics, renal pathologic changes, and follow-up information were analyzed in detail.

This study was approved by the institutional review boards at Weill Cornell Medical College and Oregon Health and Science University.

\section{Results}

The clinical parameters at the time of biopsy are summarized in table 1 . The patients with diffuse mesangial glomerulosclerosis ranged in age from 58-80 (mean 70), were Caucasian, and 5 of 6 were men. The patients in the nodular group were 48-72 years old (mean 62) and all Caucasian men. All patients in the study were smokers and the smoking duration was extensive in both groups, 
Table 1. Clinical parameters of patients with long-standing smoking and hypertension in the absence of diabetes, biopsied for proteinuria

\begin{tabular}{|c|c|c|c|c|c|c|c|c|}
\hline & Age & $\begin{array}{l}\text { Smoking } \\
\text { history, } \\
\text { mean (years) }\end{array}$ & $\begin{array}{l}\text { Active } \\
\text { smokers, } \\
\mathrm{n}(\%)\end{array}$ & $\begin{array}{l}\text { HTN, } \\
\text { n (\%) }\end{array}$ & $\begin{array}{l}\text { Coronary } \\
\text { artery disease, } \\
\mathrm{n}(\%)\end{array}$ & $\mathrm{Cr}, \mathrm{mg} / \mathrm{dl}$ & $\begin{array}{l}\text { Proteinuria, } \\
\mathrm{g} / 24 \mathrm{~h}\end{array}$ & $\begin{array}{l}\text { Hematuria, } \\
\mathrm{n}(\%)\end{array}$ \\
\hline Diffuse (6) M:F - 5:1 & $58-80($ mean 70$)$ & 42 & $3(50)$ & $6(100)$ & $3(50)$ & $1.8(1.1-2.4)$ & $4.6(1.9-7)$ & $1(17)$ \\
\hline Nodular (4) M:F - 4:0 & $48-72($ mean 62$)$ & 23 & $2(50)$ & $4(100)$ & $2(50)$ & $1.9(1.3-3.0)$ & $3.0(1.75-5.5)$ & $1(25)$ \\
\hline
\end{tabular}

Table 2. Pathologic findings on kidney biopsy from patients with long-standing smoking and hypertension

\begin{tabular}{|c|c|c|c|c|c|c|c|c|c|c|}
\hline & $\begin{array}{l}\text { Total } \\
\text { glomeruli, } \\
\text { range }\end{array}$ & $\begin{array}{l}\text { Global } \\
\text { GS, } \\
\text { mean (\%) }\end{array}$ & $\begin{array}{l}\text { Segmenta } \\
\text { GS }\end{array}$ & I Glomerulomegaly & $\begin{array}{l}\text { Mesangial } \\
\text { expansion }\end{array}$ & $\begin{array}{l}\text { TMA } \\
\text { changes }\end{array}$ & $\begin{array}{l}\text { IF/TA, } \\
\text { mean } \\
(\%)\end{array}$ & $\begin{array}{l}\text { Vascular } \\
\text { sclerosis }\end{array}$ & $\begin{array}{l}\text { GBM } \\
\text { thickness, } \\
\text { mean } \\
(\mathrm{nm})\end{array}$ & $\begin{array}{l}\text { Foot } \\
\text { process } \\
\text { effacement, } \\
\%\end{array}$ \\
\hline $\begin{array}{l}\text { Diffuse } \\
\text { (6 patients) }\end{array}$ & $11-30$ & $30(18-72)$ & $1 / 6$ cases & $\begin{array}{l}6 / 6 \text { cases } \\
\text { (moderate) }\end{array}$ & $\begin{array}{l}\text { mild } 4 \\
\text { severe } 2\end{array}$ & $\begin{array}{l}\text { CW double } \\
\text { contours } 4 / 6 \\
\text { subendothelial } \\
\text { widening } 5 / 6\end{array}$ & $\begin{array}{l}42 \\
(10-70)\end{array}$ & $\begin{array}{l}\text { moderate } \\
3 / 6 \\
\text { severe } \\
2 / 6\end{array}$ & $\begin{array}{l}530 \\
(300-750)\end{array}$ & $15-90$ \\
\hline $\begin{array}{l}\text { Nodular } \\
\text { (4 patients) }\end{array}$ & $5-33$ & $24(6-60)$ & not seen & $\begin{array}{l}4 / 4 \text { cases } \\
\text { (moderate } \\
\text { to severe) }\end{array}$ & nodular 4 & $\begin{array}{l}\text { CW double } \\
\text { contours } 1 / 4 \\
\text { subendothelial } \\
\text { widening } 2 / 4\end{array}$ & $\begin{array}{l}48 \\
(35-60)\end{array}$ & $\begin{array}{l}\text { moderate } \\
1 / 4 \\
\text { severe } \\
3 / 4\end{array}$ & $\begin{array}{l}683 \\
(550-750)\end{array}$ & $15-20$ \\
\hline
\end{tabular}

GS = Glomerulosclerosis; TMA = thrombotic microangiopathy; IF/TA = interstitial fibrosis/tubular atrophy; GBM = glomerular basement membrane; CW = capillary wall.

20-51 years (actual years, not pack years - although most were 1 pack per day smokers) in diffuse (mean 42 years) and 20-30 years for nodular (mean 23 years). Three of the diffuse and 2 nodular patients remained active smokers at the time of the biopsy, while the remainder were reformed. In 2 patients, the duration of smoking cessation was unknown, but 3 patients had quit 14, 20 and 35 years prior to biopsy. Hypertension was present in all individuals (range: 140s to 170s systolic) and all were on at least 2 anti-hypertensive medications (range: $2-3$ ). Peripheral vascular disease or coronary artery disease was also present in $2(33 \%)$ and $2(50 \%)$ of the patients with either diffuse or nodular mesangial glomerulosclerosis, respectively. The majority $(80 \%)$ of patients were not obese, weighing between 138 and 233 lbs (BMI 23-35.5). Two patients fell into the obese category at BMI of 31.7 and 35.5, but both had Hgb Alc testing within the normal range, 5.5 and $5.6 \%$, to exclude diabetes. All serologies tested were negative. There was no history of malignant range hypertension, chemotherapy use, hemolytic uremic syndrome or thrombotic thrombocytopenia purpura, scleroderma, or presence of anti-phospholipid antibodies.
At the time of biopsy, all patients had some degree of chronic renal insufficiency. Creatinine values ranged from 1.1-2.4 mg/dl for the diffuse (mean 1.8) and 1.4$3 \mathrm{mg} / \mathrm{dl}$ for the nodular (mean 1.9). For the combined groups, the mean creatinine value was $1.9 \mathrm{mg} / \mathrm{dl}$. Proteinuria was also present in all patients and was the main indication for biopsy. Proteinuria levels were 1.9-7 g/24 h (mean 4.6) for diffuse and 1.75-5.5 g/24 h (mean 3.0) for the nodular. In all, mean proteinuria was $3.9 \mathrm{~g} / 24 \mathrm{~h}$ for both groups combined. Two patients had microscopic hematuria at the time of biopsy.

The renal pathologic findings are shown in table 2 . Diffuse mesangial glomerulosclerosis was seen globally in the 6 patients in that group, while nodular mesangial glomerulosclerosis was the defining feature of the nodular group (fig. 1). Total glomeruli sampled ranged from 11-30 in the diffuse group and 5-33 in the nodular group, with $18-72 \%$ (mean $30 \%$ ) and $6-60 \%$ (mean $24 \%$ ) of glomeruli in each group, respectively, being globally sclerosed. One of 6 diffuse cases also showed segmental sclerosis in $8 \%$ of glomeruli. None of the glomeruli with nodular glomerulosclerosis showed segmental sclerosis. Glomerulomegaly was seen in all cases, 

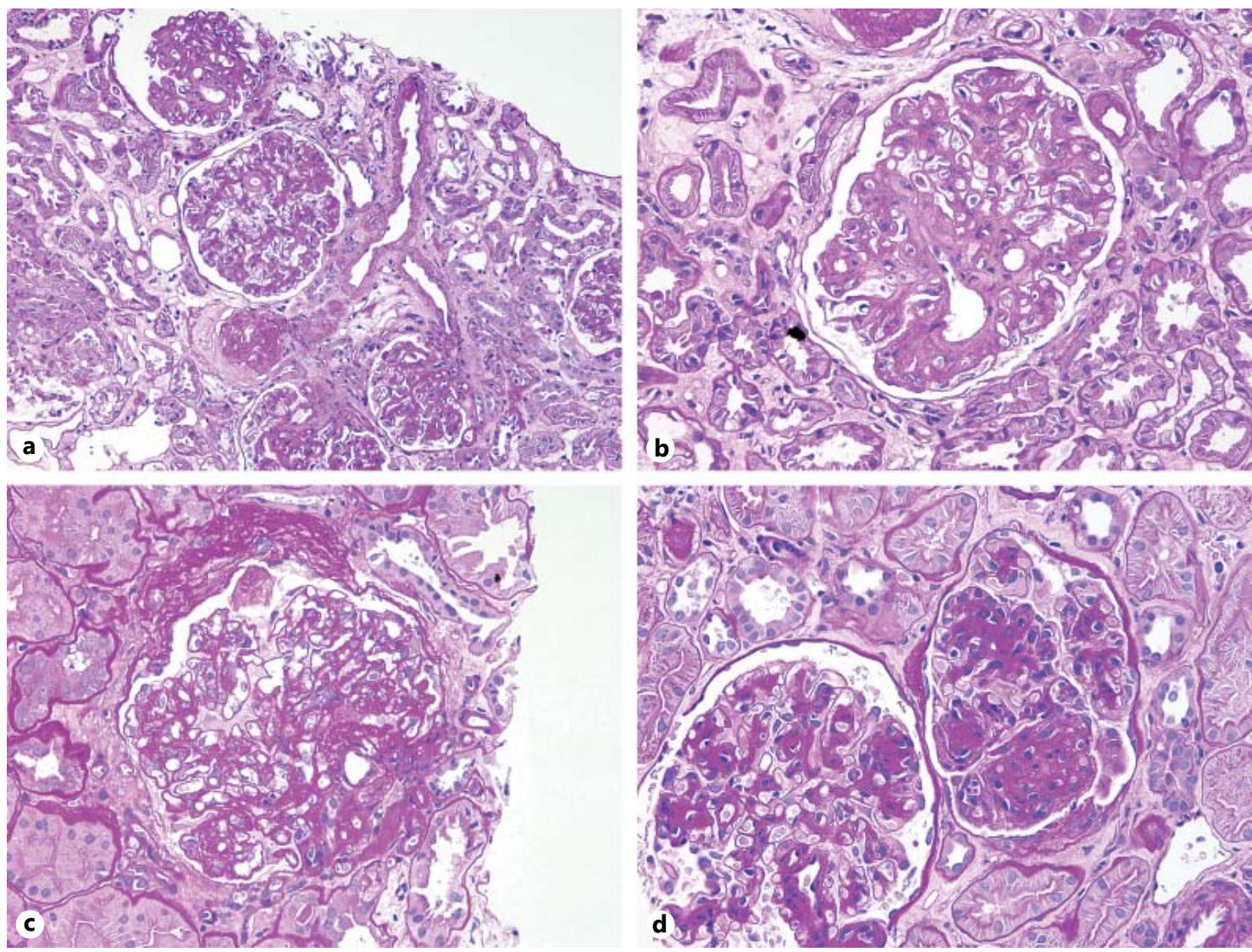

Fig. 1. Light microscopic changes in smoking related glomerulopathy. Diffuse (a-c) and nodular (d) mesangial glomerulosclerosis. Hilar neovascularization was commonly observed as was capillary wall double contour formation (c). Mesangial neovascularization was also present (d). Periodic acid Schiff, original magnification $\times 20$ (a), $\times 40$ (b-d).

defined as glomerular size being greater than $50 \%$ of a $40 \times$ field when visualized with a cut through of the hilum. Of the diffuse glomerulosclerosis cases, the mesangial expansion was mild in 4 and severe in 2, based on the amount of area with increased mesangial matrix present (scored as less than a capillary lumen = mild and greater than a capillary lumen $=$ severe). Arteriolar intimal hyalinosis was seen in 8 of 10 biopsies with circumferential or nodular distribution of the arteriolar intimal layers.

Changes of chronic thrombotic microangiopathy were also frequently seen. By light microscopy, 4 of 6 cases of diffuse mesangial glomerulosclerosis and 1 of 4 nodular mesangial glomerulosclerosis had double contours of the capillary walls. On EM, subendothelial widening was present in 5 of 6 diffuse and 2 of 4 nodular cases, and glomerular basement membrane duplication in 3 of 6 diffuse and 2 of 4 nodular cases (fig. 2).

Smoking-Related Glomerulopathy
Interstitial fibrosis and tubular atrophy were present in all cases, ranging from $10-70 \%$ (mean $42 \%$ ) of the renal cortical tissue in the cases with diffuse mesangial sclerosis and 35-60\% (mean 48\%) of nodular cases. Vascular sclerosis of both the small arteries showing fibrointimal sclerosis and arterioles revealing medial hypertrophy was moderate in $3 / 6$ diffuse and $1 / 4$ nodular and severe in 2/6 diffuse and 3/4 nodular. Increased prominent hilar region neovascularization or mesangial neovascularization by light and/or electron microscopy were also frequently observed, in $3 / 10$ and $6 / 10$ cases, respectively (fig. 1c).

Using electron microscopy it was found that the glomerular basement membranes were thickened, ranging from 300-750 nm (mean $530 \mathrm{~nm}$ ) for diffuse and 550$750 \mathrm{~nm}$ (mean $683 \mathrm{~nm}$ ) for nodular. Foot process effacement overlying the thickened basement membranes was seen in 15-90\% (mean 41\%): 15-90\% diffuse and 15-20\% 

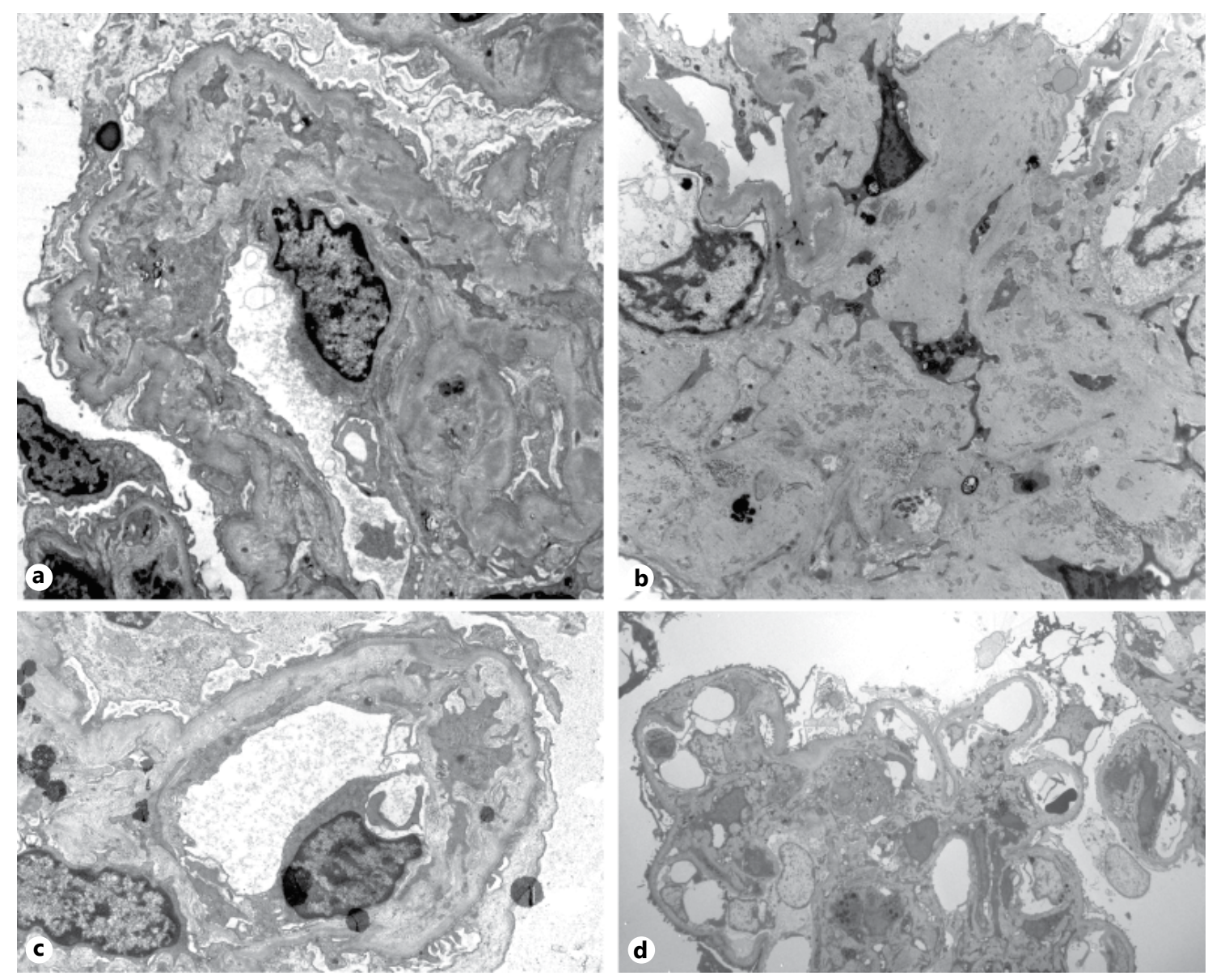

Fig. 2. Electron microscopic findings of endothelial injury with glomerular basement membrane duplication and cellular interposition $(\mathbf{a}, \mathbf{c})$. Increased mesangial matrix (b) and vascularity (d) were also seen. Original magnification $\times 4,400(\mathbf{a}), \times 2,900(\mathbf{b}), \times 6,000(\mathbf{c}), \times 1,800(\mathbf{d})$.

nodular. One case showed focal fibrillary degeneration of the collagen matrix along the subendothelial zone.

No cases showed evidence of immune complex deposits based on negative immunofluorescence microscopy for IgG, IgM, IgA, C3, C1q and kappa and lambda light chains as well as the absence of electron dense deposits by electron microscopy.

Follow-up data was available for 7 patients (5 diffuse and 2 nodular). The length of follow-up ranged from 5 months to 4.5 years. Two patients, 1 with diffuse mesangial glomerulosclerosis and 1 with nodular mesangial glomerulosclerosis, who both had severe vascular sclerosis, became dialysis dependent, 5 months and 2 years after biopsy. The other patients had insidious rise in creatinine levels with persistent proteinuria without significant decline in renal function. Four of the 7 patients with followup quit smoking successfully at the time of the last followup.

\section{Discussion}

Smoking and hypertension have previously been associated with so-called ING [2] and anecdotally a diffuse pattern of mesangial sclerosis has also been mentioned [7], but this is the first fully characterized report of diffuse mesangial glomerulosclerosis in patients with longstanding smoking and hypertension who do not have diabetes. Herein, we report a cohort of 10 patients who have pathologic features of diffuse or nodular mesangial glomerulosclerosis with longstanding history of smoking and hypertension in the absence of diabetes. The majority of the patients have severe peripheral vascular disease, severe arteriosclerosis in the kidney, and features of chronic thrombotic microangiopathy on renal biopsy. We postulated that smoking and hypertension lead to chronic endothelial injury in some patients, which induces pathologic alterations akin to that seen in diabetic nephropa- 
thy, with both diffuse and nodular mesangial sclerosis, and manifests clinically as chronic renal insufficiency and proteinuria.

The pathologic differential diagnosis for the pattern of diffuse mesangial glomerulosclerosis with chronic endothelial injury includes entities such as diabetic nephropathy, chronic thrombotic microangiopathy from any cause, chronic membranoproliferative glomerulonephritis (MPGN), glomerulopathy from myeloproliferative neoplasms [9], and now described diffuse smoking-related glomerulopathy. With the exception of chronic MPGN, where immunofluorescence microscopy reveals immune complex or $\mathrm{C} 3$ deposits, the remaining diagnoses all necessitate a thorough clinical and social history including adequate laboratory testing to examine impaired glucose metabolism or underlying hematological disease. Rarely patients with myeloproliferative neoplasms may show diffuse mesangial sclerosis and endothelial injury presenting with nephrotic range proteinuria and chronic renal insufficiency as a late manifestation of the disease with a slowly progressing course. The mesangial expansion is presumably due to platelet derived cytokines (PDGF and TGF-Beta) and the endothelial injury is thought to be caused by platelet aggregation leading to capillary wall double contours [9].

The patients presented herein have a similar spectrum of renal pathologic features usually seen in DN, where hyperglycemia induces glomerular, tubular, and vascular pathologic changes. As described in the classification of diabetic nephropathy [8], glomerular changes can be mild with isolated thickening of the glomerular capillary basement membranes, or more marked with diffuse mesangial glomerulosclerosis, nodular mesangial glomerulosclerosis, or advanced/sclerosing glomerular changes. Although diffuse versus nodular mesangial sclerosis may have a different pathogenesis, both may be present concurrently in DN biopsy tissue. A different pathogenesis may also exist for diffuse versus nodular SRG, but more study will be needed in this area. Tubular basement membrane thickening, vascular sclerosis and hyalinosis, and glomerular mesangial neovascularization are also commonly present, both in DN and SRG [8].

Cigarette smoking has known deleterious effects on renal function. Chronic smokers have been shown to have clinical renal impairment $[10,11]$ and to have increased urinary albumin concentrations [12]. In our patients, the cases with diffuse mesangial glomerulosclerosis had higher levels of creatinine and proteinuria than the nodular cases. In patients who are hypertensive and chronic smokers, Tylicki et al. have shown an association

Smoking-Related Glomerulopathy between smoking and urinary albumin as well as increased features of oxidative stress in hypertensive smokers as seen by increased levels of urinary isoprostanes [13]. Chronic endothelial injury in smoking leads to a reduced renal plasma flow and increased endothelin-1 concentrations [14]. Histopathologically, the endothelial injury is associated with vascular myointimal hyperplasia and hyalinosis leading to global glomerulosclerosis [15].

Within the glomeruli, nicotine has known effects on the endothelium as well as the mesangial cells. In the rat model, mesangial cells exhibit increased expression of TGF-beta and lipid peroxidation in response to nicotine, which is likely mediated by the mesangial cell nicotine acetylcholine receptor also found on human mesangial cells $[16,17]$. In vitro studies reveal that the human mesangial cell responds to nicotine exposure in a stereotypical way with dose-dependent proliferation and an increase in fibronectin production (a surrogate for increased matrix production) [16]. This effect is amplified in mouse models of preexisting chronic kidney disease, diabetic glomerular disease, or acute nephritis [18-20]. Non-neuronal nicotinic acetylcholine receptors are also present on endothelial cells, which may play a role in angiogenesis and endothelial cell proliferation [21]. In all, similar mechanisms of renal fibrosis seen in $\mathrm{DN}$ are likely playing a role in SRG, thereby presenting with similar clinical manifestations and pathologic appearance on biopsy.

While smoking prevalence continues to decrease in the United States, it remains high even in other nations around the world. An obvious question would be 'why do some smokers manifest renal impairment and necessitate biopsy and others do not?' The answer is not entirely clear. It is also not known why some poorly controlled diabetics manifest $\mathrm{DN}$, while others do not. What drives the pathologic development of diffuse compared to nodular mesangial sclerosis either in DN or smoking and hypertension is also not known. There are likely both genetic and environmental factors that induce individual susceptibility to manifest clinical renal disease. Concomitant hypertension may also be necessary to enhance the glomerular injury and pathologic findings in both settings. Future studies using emerging molecular pathologic techniques may uncover the expression of additional high-risk genes and molecular pathways, which may further elucidate the underlying pathogenetic mechanisms.

Chronic endothelial injury in the setting of hypertension and chronic smoking may cause proteinuria and chronic renal insufficiency showing either diffuse or nodular mesangial glomerulosclerosis on biopsy. In fact, the diffuse mesangial glomerulosclerosis may be more fre- 
quently present in the biopsy, but may be missed or ignored due to its nonspecific nature. This diagnosis, detected earlier, may be critical in inducing reversibility with proper patient counseling. It is therefore important for the nephrologist to obtain smoking history and for the renal pathologist to recognize this pathologic entity and its risk factors and to exclude other potential lesions by performing a systematic analysis of the biopsy employing LM, IF, and EM for the ultimate purpose of aiding the nephrologist in appropriate treatment and counseling.

\section{Acknowledgments}

The authors would like to thank Drs. Nazifa Banu, Joshua Kaplan, Kendall Michels, Brett Mikeska, Julie Raggio, and Suzanne Watnick, for their contributions of clinical history and follow-up information.

\section{Financial Disclosures}

The authors have nothing to disclose.

\section{References}

1 Li W, Verani RR: Idiopathic nodular glomerulosclerosis: a clinicopathologic study of 15 cases. Hum Pathol 2008;39:1771-1776.

2 Markowitz GS, Lin J, Valeri AM, Avila C, Nasr SH, D’Agati VD: Idiopathic nodular glomerulosclerosis is a distinct clinicopathologic entity linked to hypertension and smoking. Hum Pathol 2002;33:826-835.

3 Kwok S, D’Agati V, Anis K, Jim B: An unusual case of nephrotic syndrome and glucosuria. Am J Kidney Dis 2012;59:734-737.

-4 Liang KV, Greene EL, Oei LS, Lewin M, Lager D, Sethi S: Nodular glomerulosclerosis: renal lesions in chronic smokers mimic chronic thrombotic microangiopathy and hypertensive lesions. Am J Kidney Dis 2007;49:552559.

5 Herzenberg AM, Holden JK, Singh S, Magil $\mathrm{AB}$ : Idiopathic nodular glomerulosclerosis. Am J Kidney Dis 1999;34:560-564.

6 Kuppachi S, Idris N, Chander PN, Yoo J: Idiopathic nodular glomerulosclerosis in a nondiabetic hypertensive smoker - case report and review of literature. Nephrol Dial Transplant 2006;21:3571-3575.

7 Nasr SH, D'Agati VD: Nodular glomerulosclerosis in the nondiabetic smoker. J Am Soc Nephrol 2007;18:2032-2036.

-8 Tervaert TW, Mooyaart AL, Amann K, Cohen AH, Cook HT, Drachenberg CB, Ferrario F, Fogo AB, Haas M, de Heer E, Joh K, Noel LH, Radhakrishnan J, Seshan SV, Bajema IM, Bruijn JA: Pathologic classification of diabetic nephropathy. J Am Soc Nephrol 2010;21: 556-563.
Said SM, Leung N, Sethi S, Cornell LD, Fidler ME, Grande JP, Herrmann S, Tefferi A, D’Agati VD, Nasr SH: Myeloproliferative neoplasms cause glomerulopathy. Kidney Int 2011;80:753-759.

10 Bleyer AJ, Shemanski LR, Burke GL, Hansen KJ, Appel RG: Tobacco, hypertension, and vascular disease: risk factors for renal functional decline in an older population. Kidney Int 2000;57:2072-2079.

11 Goetz FC, Jacobs DR Jr, Chavers B, Roel J, Yelle M, Sprafka JM: Risk factors for kidney damage in the adult population of Wadena, Minnesota. A prospective study. Am J Epidemiol 1997;145:91-102.

12 Hillege HL, Janssen WM, Bak AA, Diercks GF, Grobbee DE, Crijns HJ, Van Gilst WH, De Zeeuw D, De Jong PE: Microalbuminuria is common, also in a nondiabetic, nonhypertensive population, and an independent indicator of cardiovascular risk factors and cardiovascular morbidity. J Intern Med 2001; 249:519-526.

13 Tylicki L, Puttinger H, Rutkowski P, Rutkowski B, Horl WH: Smoking as a risk factor for renal injury in essential hypertension. Nephron Clin Pract 2006;103:c121-c128.
14 Gambaro G, Verlato F, Budakovic A, Casara D, Saladini G, Del Prete D, Bertaglia G, Masiero M, Checchetto S, Baggio B: Renal impairment in chronic cigarette smokers. J Am Soc Nephrol 1998;9:562-567.

15 Lhotta K, Rumpelt HJ, Konig P, Mayer G, Kronenberg F: Cigarette smoking and vascular pathology in renal biopsies. Kidney Int 2002;61:648-654.

16 Jaimes EA, Tian RX, Raij L: Nicotine: the link between cigarette smoking and the progression of renal injury? Am J Physiol Heart Circ Physiol 2007;292:H76-H82.

17 Mur C, Claria J, Rodela S, Lario S, Campistol JM, Titos E, Inigo P, Cases A, Abian J, Esmatjes E: Cigarette smoke concentrate increases 8-epi-PGF2alpha and TGFbetal secretion in rat mesangial cells. Life Sci 2004;75: 611-621.

18 Hua P, Feng W, Ji S, Raij L, Jaimes EA: Nicotine worsens the severity of nephropathy in diabetic mice: implications for the progression of kidney disease in smokers. Am J Physiol Renal Physiol 2010;299:F732-F739.

19 Rezonzew G, Chumley P, Feng W, Hua P, Siegal GP, Jaimes EA: Nicotine exposure and the progression of chronic kidney disease: role of the $\alpha 7$-nicotinic acetylcholine receptor. Am J Physiol Renal Physiol 2012;303:F304-F312.

20 Jaimes EA, Tian RX, Joshi MS, Raij L: Nicotine augments glomerular injury in a rat model of acute nephritis. Am J Nephrol 2009;29: 319-326.

21 Lee J, Cooke JP: Nicotine and pathological angiogenesis. Life Sci 2012;91:1058-1064. 